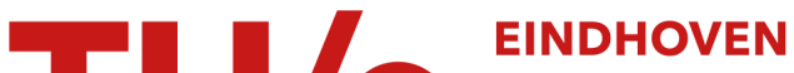 \\ UNIVERSITY OF \\ TECHNOLOGY
}

\section{Evaluating peripheral interaction design}

Citation for published version (APA):

Bakker, S., Hoven, van den, E. A. W. H., \& Eggen, B. (2015). Evaluating peripheral interaction design. HumanComputer Interaction, 30(6), 473-506. https://doi.org/10.1080/07370024.2014.921531

\section{Document license:}

TAVERNE

DOI:

10.1080/07370024.2014.921531

Document status and date:

Published: 01/01/2015

\section{Document Version:}

Publisher's PDF, also known as Version of Record (includes final page, issue and volume numbers)

\section{Please check the document version of this publication:}

- A submitted manuscript is the version of the article upon submission and before peer-review. There can be important differences between the submitted version and the official published version of record. People interested in the research are advised to contact the author for the final version of the publication, or visit the $\mathrm{DOI}$ to the publisher's website.

- The final author version and the galley proof are versions of the publication after peer review.

- The final published version features the final layout of the paper including the volume, issue and page numbers.

Link to publication

\section{General rights}

Copyright and moral rights for the publications made accessible in the public portal are retained by the authors and/or other copyright owners and it is a condition of accessing publications that users recognise and abide by the legal requirements associated with these rights.

- Users may download and print one copy of any publication from the public portal for the purpose of private study or research.

- You may not further distribute the material or use it for any profit-making activity or commercial gain

- You may freely distribute the URL identifying the publication in the public portal.

If the publication is distributed under the terms of Article 25fa of the Dutch Copyright Act, indicated by the "Taverne" license above, please follow below link for the End User Agreement:

www.tue.nl/taverne

Take down policy

If you believe that this document breaches copyright please contact us at:

openaccess@tue.nl

providing details and we will investigate your claim. 


\section{Evaluating Peripheral Interaction Design}

\section{Saskia Bakker, Elise van den Hoven \& Berry Eggen}

To cite this article: Saskia Bakker, Elise van den Hoven \& Berry Eggen (2015) Evaluating Peripheral Interaction Design, Human-Computer Interaction, 30:6, 473-506, DOI:

10.1080/07370024.2014.921531

To link to this article: http://dx.doi.org/10.1080/07370024.2014.921531

Accepted author version posted online: 12 May 2014.

Submit your article to this journal $\pi$

III Article views: 521

Q View related articles $₫$

View Crossmark data $₫$

4 Citing articles: 1 View citing articles 준 


\title{
Evaluating Peripheral Interaction Design
}

\author{
Saskia Bakker, ${ }^{1}$ Elise van den Hoven, ${ }^{1,2}$ and Berry Eggen ${ }^{1}$ \\ ${ }^{1}$ Eindhoven University of Technology, the Netherlands \\ ${ }^{2}$ University of Technology, Sydney, Australia
}

\begin{abstract}
Many actions in the physical world take place in the background or periphery of people's attention. However, interactions with computing technologies usually require focused attention. This article explores the concept of peripheral interaction: physical interaction with technology that takes place outside the focus of attention. A peripheral interaction design (called FireFlies), which supports primary school teachers in their everyday routine through open-ended light-objects on the children's desks, was deployed in 4 classrooms for 6 weeks. Results of interviews and video analysis indicate that the 6 participating teachers were able to physically interact with the FireFlies interactive artifact quickly and frequently without disturbing ongoing tasks. In the final weeks of the study, the teachers seemed able to easily shift their focus of attention between their main task and the interactive system. We therefore conclude that, even though it is difficult to measure people's attention, a longitudinal approach seemed effective to find indicators for peripheral interaction.
\end{abstract}

\footnotetext{
Saskia Bakker (s.bakker@tue.nl, www.saskiabakker.com) is a design researcher with an interest in research-through-design in everyday environments; she is an Assistant Professor in the Industrial Design Department of the Eindhoven University of Technology. Elise van den Hoven (elise.vandenhoven@uts.edu.au,www.elisevandenhoven.com) is a design researcher with an interest in designing physical interaction in an everyday context; she is an Associate Professor in the Design, Architecture \& Building Faculty of the University of Technology, Sydney, and in the Industrial Design Department of the Eindhoven University of Technology. Berry Eggen (j.h.eggen@tue.nl, www.berryeggen.com) is a design researcher with an interest in information ergonomics, multimodal interaction (including light and sound), and intelligent user interfaces; he is a Full Professor at the Industrial Design department of the Eindhoven University of Technology and an Adjunct Professor at the Design, Architecture \& Building faculty of the University of Technology, Sydney.

Color versions of one or more of the figures in the article can be found online at www.tandfonline. com/hhci.
} 


\section{CONTENTS}

1. INTRODUCTION

2. THE CENTER AND PERIPHERY OF ATTENTION

3. RELATED WORK

3.1. Related Designs

3.2. Related Evaluation Strategies

4. PERIPHERAL INTERACTION DESIGN: FIREFLIES

5. USER EVALUATION

5.1. Evaluation Setup

5.2. Indicators of Peripheral Interaction Used

5.3. Data Analysis Procedure

6. FINDINGS AND DISCUSSION OF FIREFLIES

6.1. How FireFlies was Used

6.2. Frequency of Observed Interactions with FireFlies

6.3. Duration of Observed Interactions with FireFlies

6.4. Interacting With FireFlies During Other Tasks

6.5. An Observed Example of Peripheral Interaction

7. DISCUSSION OF PERIPHERAL INTERACTION

7.1. Peripheral Interaction and the Everyday Routine

7.2. Shifts Between the Center and Periphery of Attention

7.3. Peripheral Interaction in a Primary School Context

8. DISCUSSION OF THE EVALUATION APPROACH

8.1. Assessing Peripheral Interaction

8.2. Duration of the Evaluation

9. CONCLUSIONS

\section{INTRODUCTION}

In the everyday world, computing technology is being integrated in numerous artifacts and environments. This development brings along many opportunities but also raises challenges. In particular, the challenge of fluently fitting new technologies into the everyday world has been addressed in several ways in human-computer interaction (HCI) literature. Many such approaches (e.g., Dourish, 2001; Ullmer \& Ishii, 2000) advocate looking at the physical world for inspiration on how to design interaction with the digital. The direction of calm technology (Weiser \& Brown, 1997) is inspired by the observation that many actions in the physical world take place in people's background or periphery of attention. For example, we are aware of all kinds of information (e.g., about the weather or the time of day) without consciously thinking about it. In addition, routine physical actions such as tying your shoelaces, washing your hands, or walking your usual route home are performed without focused attention (Norman \& Shallice, 1986). 
In contrast to traditional methods of HCI (e.g., keyboard and screen), which typically require the user's focused attention, interactions with the everyday world clearly shift between the center and periphery of attention. Given that technology is becoming more pervasive in everyday life, we see a large added value in interactive systems that may similarly reside in the periphery of attention while shifting to the center of attention only when relevant. We believe that this approach will support computing technology to better fit into everyday life routines.

Although initially presented as calm technology (Weiser \& Brown, 1997), the idea of employing people's periphery of attention in interaction with technology has been explored under many terms including peripheral displays (Matthews, Hsieh, \& Mankoff, 2009; Matthews, Rattenbury, \& Carter, 2007) and ambient information systems (Pousman \& Stasko, 2006). Most related work aims at subtly presenting information to provide awareness through peripheral perception (Cohen, 1993; Eggen \& Mensvoort, 2009; Ishii et al., 1998). Inspired by the observation that in everyday life both perception and action can take place in the periphery, a few recent studies (Bakker, Hoven, \& Eggen, 2013; Edge \& Blackwell, 2009; Hausen, Boring, Lueling, Rodestock, \& Butz, 2012; Olivera, García-Herranz, Haya, \& Llinás, 2011) have proposed extending this area by designing not only for the perceptual periphery but also to enable users to physically interact with the digital world in their periphery. This direction is referred to as peripheral interaction (Bakker et al., 2013; Hausen et al., 2012; Olivera et al., 2011). Although peripheral interaction can encompass both perception and physical interaction, the focus of the present article is on physical interactions with technology in the user's periphery of attention.

As we know from related studies aimed at employing the periphery of attention, one of the major challenges is the evaluation of designs (Hazlewood, Stolterman, \& Connelly, 2011; Mankoff et al., 2003; McCrickard, Chewar, Somervell, \& Ndiwalana, 2003; Shami, Leshed, \& Klein, 2005). A number of strategies for evaluating such designs are known that are suitable for short-term experiments in a laboratory setting (Hazlewood et al., 2011). Such experiments are an essential part of the development process as they provide insights into the potential of a design and raise points for improvement early in the process. Because peripheral interaction designs are meant to blend into the everyday environment, however, such laboratory experiments may not always be suitable in later stages of the process, when evaluating designs that have been developed into functional prototypes. As a period of getting used to working with a new technology is usually required, conducting long-term evaluations in the intended context of use is important to understand the extent to which a design can be used in the periphery of attention and blend into everyday routines.

In this article we evaluate whether people can indeed physically interact with a prototype system designed for use in the periphery of attention. Thereby we aim to contribute to HCI research by suggesting a longitudinal field evaluation strategy suitable for peripheral interaction. In this article, we apply this evaluation strategy in a study with a peripheral interaction design called FireFlies (Bakker et al., 2013). FireFlies is an open-ended design aimed to support teachers' secondary tasks through straightforward interaction with a physical artifact. We deployed FireFlies in four primary 
school classrooms for 6 weeks each. Video and interview data obtained during the study were assessed to evaluate if the six teachers who worked with FireFlies were able to physically interact with it in their periphery of attention. Before presenting the details of our study and the applied evaluation strategy, we first discuss the background of attention theory and related work.

\section{THE CENTER AND PERIPHERY OF ATTENTION}

The concept of peripheral interaction is grounded in divided attention theory (Kahneman, 1973; Wickens \& McCarley, 2008), visualized in Figure 1 (Bakker, Hoven, \& Eggen, 2010). Divided attention theory originates in the observation that in any situation, multiple activities can potentially be undertaken. Because not all of these activities can be performed at the same time, we need to choose which activities to devote our attention to. Models of divided attention therefore center around a number of potential activities that one can perform as a result of sensorial or intellectual information input. These potential activities are illustrated in Figure 1 as vertical bars and can be bodily activities such as walking, cognitive activities such as daydreaming, sensorial activities such as listening to the radio, or a combination of these three.

FIGURE 1. Illustration of the center and periphery of attention: division of resources during a high attentional task (left) and a combination of low attentional tasks (right).
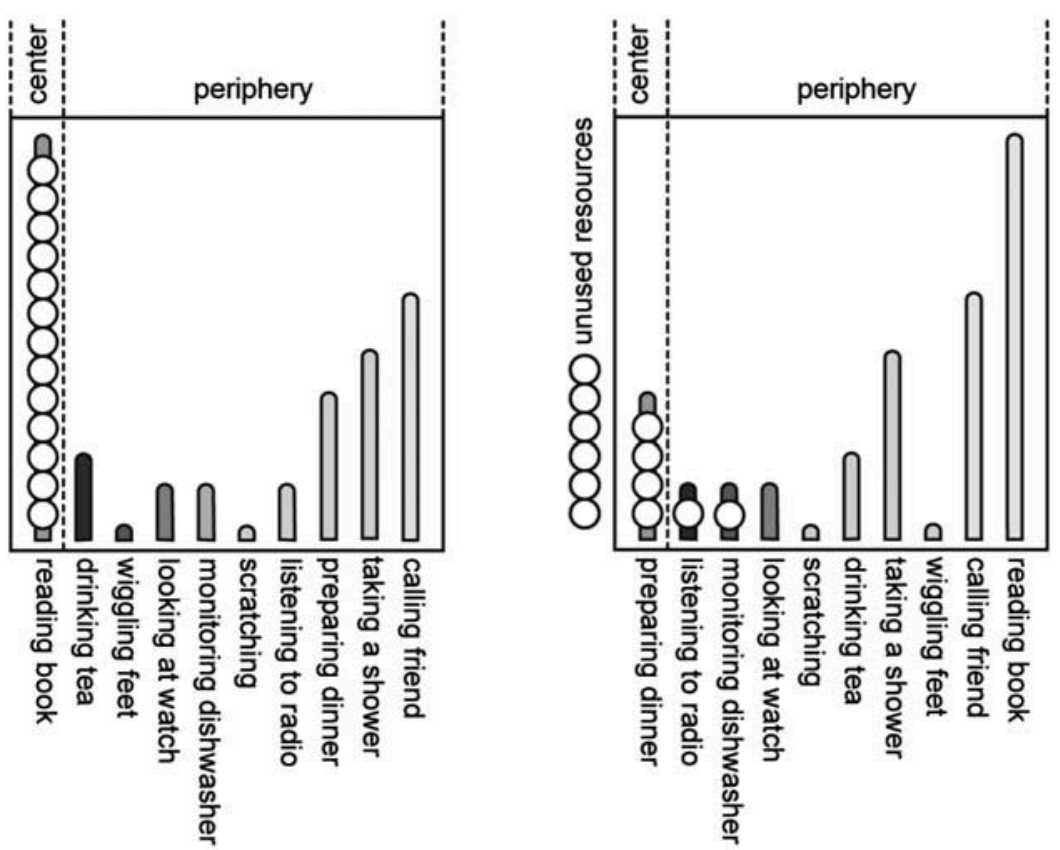

Note. Vertical bars represent potential activities that are performed when resources (white circles) are allocated to them. 
As described by divided attention theory, potential activities can be performed only when mental resources (Kahneman, 1973), illustrated as circles in Figure 1, are allocated to them. As a finite amount of mental resource is available, at most a few activities can be performed at once. Attention is therefore described as the division of mental resources over potential activities.

Not all activities require the same amount of resources to be performed. For example, reading a difficult text is more demanding than walking. The resource demand of an activity, illustrated as the length of bars in Figure 1, depends on the difficulty and automaticity of the activity. Automated processes, activities in which one is very experienced, have been trained extensively and consistently (Schneider \& Chein, 2003) and therefore require only few mental resources. Related to the concept of automaticity is the term habit or habitual behavior (Aarts \& Dijksterhuis, 2000; Wood \& Neal, 2007), "a form of goal-directed automatic behavior" (Aarts \& Dijksterhuis, 2000 , p. 55). The strength of the association between goal and action is enhanced when the action is performed more frequently.

Some potential activities may, at certain moments, be more likely to be performed than others. For example when cooking, one is more likely to open the refrigerator than to start typing an e-mail on the laptop at the kitchen table, even though both activities are equally available. These processes are managed by the supervisory attentional system (Shallice \& Burgess, 1993). The likelihood of an activity being performed is represented in Figure 1 by the brightness of bars; the darker the bar, the more likely the activity is to be performed.

Apart from their likelihood of being performed, certain activities may also be more suitable to take place simultaneously. Performing two activities at the same time, known as concurrent multitasking (Salvucci \& Taatgen, 2010), is thus feasible only under certain conditions. For example, it is rather difficult to drive a car and read a book at the same time, but driving while listening to the same book on tape is possible. As described by multiple resource theory (Wickens \& McCarley, 2008), bodily activities are more easily performed simultaneous to sensorial activities compared to performing two bodily activities at the same time. Taking this view a step further, Salvucci and Taatgen (2008) distinguished procedural resources from peripheral resources such as cognitive, perceptual, and motor resources. Their model of threaded cognition regards each activity (e.g., calling a colleague) as a separate task thread, each of which is coordinated sequentially by procedural resources (e.g., when focused attention is required to retrieve the phone number from the colleague's business card) but executed concurrently across various peripheral resources (e.g., perceptual resources to locate the digits on the phone and motor resources to select them). Mental resources can therefore not arbitrarily be divided over activities, but the division depends on the types of activities and on their stage of execution.

In line with theory of divided attention, we describe the center of attention as the one activity to which most mental resources are currently allocated. The periphery consists of all other potential activities regardless of whether mental resources are allocated to them or not (see Figure 1). An activity can thus be performed in the periphery of attention when another activity is being performed simultaneously in the center of 
attention, which requires more but not all mental resources. Given this description, a peripheral interaction design is an interactive system that a user can interact with while performing another, more demanding activity.

\section{RELATED WORK}

Our research focuses on interactions with technology that take place in the periphery and can shift to the center of attention when relevant. We now discuss related work in both design and evaluation of peripheral interaction.

\subsection{Related Designs}

Because Weiser and Brown (1997) introduced the notion of calm technology, many designs have been developed to employ the periphery of attention. AmbientROOM (Ishii et al., 1998) uses audio and visuals to convey relevant, peripheral information to office workers. ShareMon (Cohen, 1993) allows computer users to monitor background file sharing events of their computer through subtle sounds. Birds Whispering (Eggen \& Mensvoort, 2009) uses subtle bird sounds to make office workers aware of the activity level in the office. These and many other related designs are known under various terms such as peripheral displays (Matthews et al., 2007), ambient media (Ishii \& Ullmer, 1997), ambient displays (Hazlewood et al., 2011), ambient information systems (Pousman \& Stasko, 2006), and awareness systems (Markopoulos, 2009). The large majority of related work focuses on peripheral perception of relevant information. However, the scope of peripheral interaction is broader, aiming also at potential physical interaction with computing technology that takes place in the periphery of attention. Such physical peripheral interactions are the focus of the work presented in this article.

A few research examples are known that aim at physical peripheral interaction. PinchWatch (Loclair, Gustafson, \& Baudisch, 2010), for example, is a wrist-worn device that recognizes gestures made with hand and fingers. Such gestures (e.g., sliding with one finger along another finger) can be performed during other activities, and they can be interpreted as input by the device, for example, to adjust the volume of a music player. PinchWatch is positioned as an example of microinteraction (Ashbrook, 2010; Wolf, Naumann, Rohs, \& Müller, 2011): "interactions with a device that take less than four seconds to initiate and complete" (Ashbrook, 2010, p. 1). Similarly, "Whack Gestures" (Hudson, Harrison, Harrison, \& LaMarca, 2010) enable people to quickly react to cues on their mobile device through short gestures. Edge and Blackwell (2009) presented peripheral tangible interaction; physical computational artifacts that are located on the side of the workspace, available to be interacted with episodically. StaTube (Hausen et al., 2012) subtly presents availability information of instant messaging contacts, and users can manipulate StaTube to quickly update their own status in the periphery of attention.

The context of the study presented in this article is the primary school classroom. A few related studies aim to peripherally present perceptual information in this 
context. Whereas only a few concrete examples are known, learning and education is specifically mentioned as a promising application area for peripheral displays (Börner, Kalz, \& Specht, 2011). Subtle Stone (Balaam, Fitzpatrick, Good, \& Luckin, 2010), for example, allows high school students to unobtrusively communicate their emotional state to the teacher. Lantern (Alavi, Dillenbourg, \& Kaplan, 2009) is a light-object located on university students' desks during instructions. Students can manipulate Lantern to indicate which exercise they are working on or to call for help. Lamberty, Adams, Biatek, Froiland, and Lapham (2011) explored the use of a large display in a primary school classroom while children were creating digital artworks. The display showed the ongoing work of all children in order to promote awareness of one another's artistic designs. Student Feedback Orb (Hazlewood et al., 2011) presents university teachers with students' feedback on their learning experience.

This article contributes to existing work by presenting a physical peripheral interaction design that is intended for use in a classroom setting. Moreover, we present a longitudinal field approach to evaluating the extent to which such designs can be physical manipulated in a user's periphery of attention.

\subsection{Related Evaluation Strategies}

Although numerous evaluation strategies are known in the area of HCI, these usually focus on the evaluation of tasks performed in the user's center of attention, and are therefore less suitable for evaluating peripheral interaction. We now discuss evaluation methods that have been applied in studies of peripheral interaction.

The literature on attention theory just reviewed not only provides insight into the human attention process but also describes numerous experiments in which people's division of attentional resources is measured. One strategy applied is the dual-task methodology (Wickens \& Hollands, 2000): Participants perform two tasks at once and their performance on these tasks is measured. For example, participants could be asked to operate a machine while performing a probe reaction task. The response time in this secondary task is then used as a performance measure that may indicate the mental effort required for the main activity. An alternative approach is to determine the workload of an activity through physiological measures, such as heart rate variability or pupil diameter (Wickens \& Hollands, 2000). These measures may reflect the resource demand of the activities being performed. A measure that is often applied in evaluation of graphical user interfaces is eye tracking (Poole \& Ball, 2006), which is used to assess which interface elements a user is attending to at different moments.

As mentioned before, numerous research studies have focused on displaying perceptual information in people's periphery of attention. A recent overview paper (Hazlewood et al., 2011) revealed that most peripheral displays are informally evaluated by having users interact with them once or twice and assessing mainly the initial enjoyment of the display (Hazlewood et al., 2011). A few more elaborate evaluations, as summarized by Hazlewood et al. (2011), focus on the functionality and usability of evaluated designs. With similar goals, a few specific evaluation techniques have been developed for displays of peripheral information. McCrickart et al. (2003) suggested 
evaluating such displays based on three critical parameters: interruption, reaction, and comprehension. Mankoff et al. (2003) suggested an adaptation of the heuristic evaluation, aimed at looking for usability problems with ambient displays, using a list of heuristics. CUEPD (Shami et al., 2005) is a method to find potential design improvements by having users perform primary tasks while a peripheral display is available in the background. Matthews et al. (2009) specified six concrete evaluation criteria for peripheral displays_- "awareness," "distraction," "learnability," "error visibility," "usefulness," and "user satisfaction." These approaches are all intended to study peripheral interaction designs through controlled experiments in a laboratory setting.

Although the traditional approach to evaluate how users interact with technology is to observe them in a controlled, laboratory-style setting, the alternative approach of deploying (prototype versions of) designs in the real context of use for a period seems to be increasingly suggested in HCI literature (Brown, Reeves, \& Sherwood, 2011; Carter, Mankoff, Klemmer, \& Matthews, 2008; Rogers, 2011). Because the objective of peripheral interaction is to fluently integrate meaningful interactive systems in everyday life, this approach seems particularly suitable for designs that employ the periphery of attention, as is also suggested in related literature (Pousman \& Stasko, 2007). Hazlewood et al. (2011), for example, suggesting implementing ambient displays "in the wild" and proposed to evaluate them by logging the number of times the system is used by conducting interviews or by assessing the effects (e.g., by counting how many people take the stairs instead of the elevator as a result of installing peripheral displays that promote using the stairs). Although Hazlewood et al.'s study was exploratory and aimed at identifying issues with in situ evaluations of ambient displays, our work extends their study by proposing a more concrete evaluation method.

The two approaches just outlined-laboratory-style experiments and field studies - each have their own characteristics and both seem essential elements of the development process of peripheral interaction. Short-term experiments in a laboratory seem particularly suitable in earlier phases of the process, in which early concepts or prototypes are assessed on criteria such as learnability and distraction. However, such approaches do not involve the design being used during the users' everyday routines. Because the integration of interactive technologies in everyday routines is key to peripheral interaction, field studies are an equally important element of the development process. Naturally, field evaluations come with a number of downsides as well. For example, prototypes need to be robust enough to function reliably in everyday use (Carter et al., 2008), which can be costly, and considerable time usually needs to be invested to run such studies. Field evaluations therefore seem most valuable later in the process in which the design has already been developed into a robust prototype. Given that a number of laboratory setting approaches are known for designs that employ the user's periphery of attention, we believe there is a need to explore field evaluation approaches that are suitable for evaluating peripheral interaction designs. Adding to existing work on evaluating peripheral interactive systems (Mankoff et al., 2003; Matthews et al., 2009; Shami et al., 2005), and in line with a more general move toward field evaluations in HCI (Brown et al., 2011; Carter et al., 2008; Rogers, 2011), we decided to implement our design in the context of use for a period of time. In this 
article, we report both on the outcomes of this study and on the usefulness of the adopted evaluation strategy for evaluating peripheral interaction.

\section{PERIPHERAL INTERACTION DESIGN: FIREFLIES}

Computing technology is making its way into the classroom, for example, in the form of computers and interactive whiteboards. Focused attention is required to interact with these systems, and teachers use them mainly for explaining the teaching material. Apart from these activities, teachers perform many other tasks such as observing how children are doing, keeping track of their progress, giving turns, giving feedback, keeping track of time, and preparing the next lesson. Some of these latter activities are performed as secondary tasks alongside other primary tasks and should therefore not require too much attention. Because we believe that many secondary tasks could be supported by technology, we see peripheral interaction design as a suitable approach to developing interactive technologies for classroom use.

The peripheral interaction design we have used in the present study is called FireFlies (Bakker et al., 2013). FireFlies is designed for classrooms of the third, fourth, and fifth grade of primary school in the Netherlands. Children in these grades are 6 to 9 years old and have their own desk in the classroom. The school day consists of several lessons in which the teacher usually first explains the teaching material to the class, after which the children work on assignments independently or in groups. The teacher then works at her own desk, walks around the classroom, or gives instructions to a (group of) child(ren) at a dedicated table in front of the classroom.

FireFlies is an open-ended design, which can be used to support different secondary tasks of teachers. The design consists of three elements: one light-object for each child; a background soundscape; and the teacher-tool, which is used by the teacher. The FireFlies design builds on earlier explorations by the authors on peripheral interaction design for classroom use (Bakker, van den Hoven, Eggen, \& Overbeeke, 2012). The design of FireFlies and the rationale behind it are extensively reported in (Bakker et al., 2013) and is briefly summarized here.

FireFlies Light-Objects and Soundscape. Each child has a light-object on his or her desk (see Figure 2). This light-object can light up in red, green, blue, or yellow, or it can be off. The light-objects can display simple information to or about a single child, and all the light-objects together form a distributed display of information about the class as a whole. Additional to this visual information, a background soundscape provides audible information about the current colors of the light-objects, using nature sounds. Both the light-objects and the soundscape may provide peripheral awareness of the current status of FireFlies. In this article, however, we focus on the teacher's (peripheral) physical interactions with FireFlies rather than on peripheral perception.

FireFlies Teacher-Tool. The teacher can control the colors of the light-objects by manipulating the teacher-tool (see Figure 3). Inspired by related physical peripheral 
FIGURE 2. FireFlies light-objects lit in different colors.
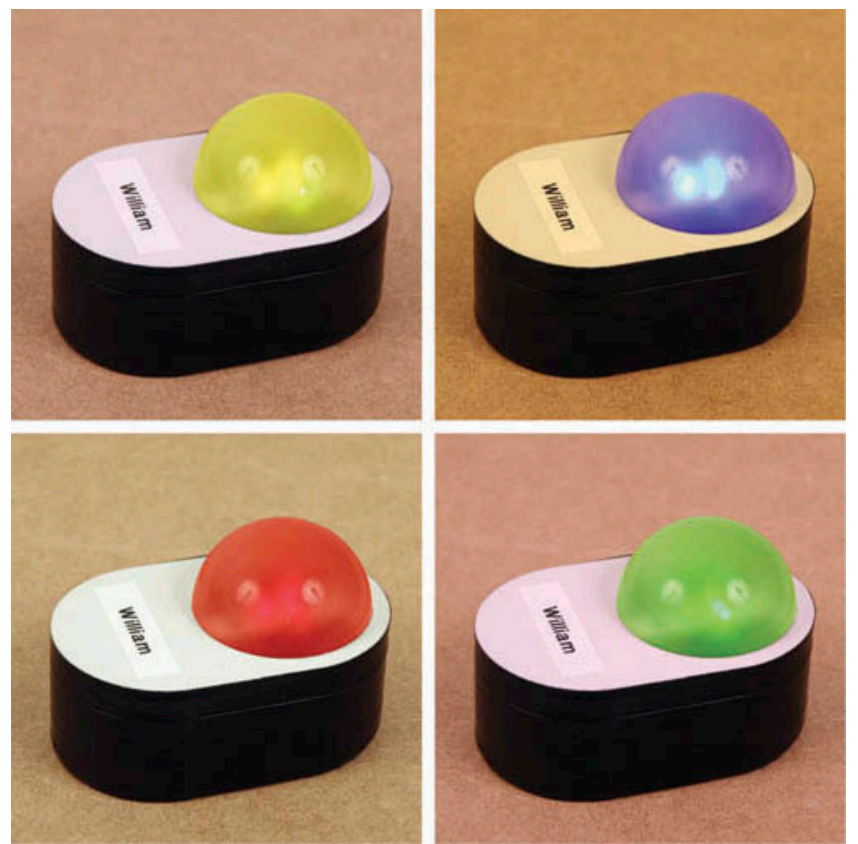

FIGURE 3. FireFlies teacher-tool: clipped to the user's clothes (left), selecting a color (middle) and selecting a child's name (right).

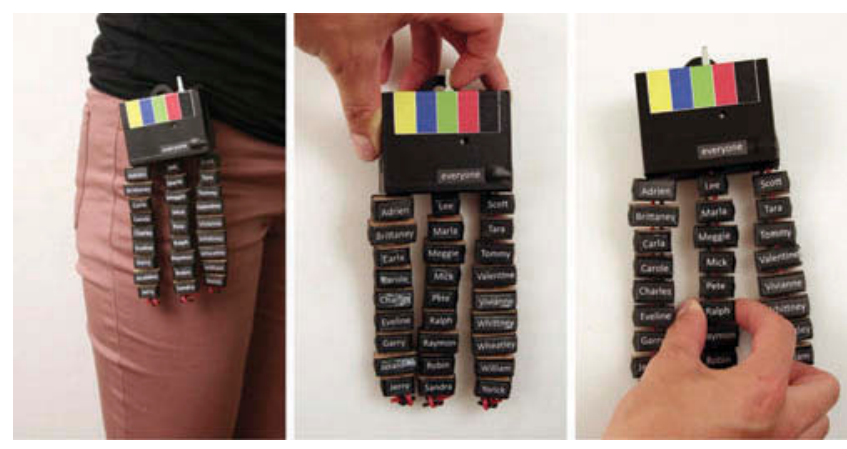

interaction designs (Hausen et al., 2012; Loclair et al., 2010) and experiences in prior work (Bakker, Hoven, \& Eggen, 2012), the teacher-tool can both be clipped to clothes to carry it around easily and be laid on a desk to be used when seated. The teacher selects a color by moving the slider on the top of the teacher-tool. The teacher can then set the light-objects of all children to this color at once by pressing a small button labeled "everyone" on the top part of the tool. Alternatively, the teacher can select children's names to change the color of individual light-objects using the beads attached 
to strings at the bottom of the tool. Each child is represented by one bead, which can be squeezed to select that child.

The interactions with the teacher-tool are intended to be quick and straightforward, such that they demand only few mental resources and can potentially be performed in the periphery of attention. The names are ordered alphabetically by first name. Furthermore, the size of each bead depends on the length of the name of the corresponding child; the longer the name, the bigger the bead. This way, both position and size of the bead provide a tactile clue of the name connected to the bead. Because teachers likely have automated knowledge of the children's names, we expected that, after getting experienced with using the teacher-tool, these design elements would support using the tool quickly and potentially in the periphery of attention.

Open-Ended Design. FireFlies is an open-ended design. The reason for choosing an open-ended design is that we know from attention theory (Aarts \& Dijksterhuis, 2000; Kahneman, 1973), as well as applied work on attention in everyday life (Bakker, Hoven, et al., 2012), that activities can shift to the periphery of attention only when the goal they serve is highly relevant to the person in question. Furthermore, technology use in classrooms depends both on the teachers' goals with the technology and on their beliefs about teaching in general (Chen, Looi, \& Chen, 2009), which may differ across teachers. The open-ended nature of FireFlies is manifested in the fact that the purpose for which it may be used is not defined but can be chosen by teachers. They may use it to instruct children which exercise they have to do, to set a reminder to go to a certain child, to give compliments, and so on.

Interactive Pototype. To perform an evaluation with FireFlies in the context of a primary school, a fully functioning interactive prototype was developed. Both the teacher-tool and the light-objects operated on rechargeable batteries so that they could be used and located anywhere in the classroom. JeeNode modules (Wippler, 2010) were used in both the teacher-tool and the light-objects to enable wireless communication and data processing.

\section{USER EVALUATION}

The aim of the work presented in this article is to explore a longitudinal field study approach to evaluate peripheral interaction. This longitudinal approach was applied in a user evaluation with our peripheral interaction design FireFlies. We used various quantitative and qualitative measures to find indications that specifically designed interactive technology could be physically manipulated in the periphery of attention and shift to the center of attention when relevant during the everyday routine. Through this study, we aim to both evaluate the potential of a longitudinal field study to evaluate peripheral interaction and explore which measures can be useful as indicators of peripheral interaction. 


\subsection{Evaluation Setup}

In our user evaluation, FireFlies was deployed in four different primary school classrooms for 6 weeks each. This would allow the intended target group to extensively experience FireFlies during different classroom situations. The four participating classes were recruited from two different primary schools; two classes of the same school participated simultaneously, each with their own set of FireFlies.

Two of the participating classes were taught by a full-time teacher, whereas the other two each had two part-time teachers, one of whom worked 2 days and the other 3 days per week. In total, 102 children of 6 to 9 years old and six different teachers worked with FireFlies for 6 weeks, even though the full-time teachers worked with it during more school days compared to the part-time teachers. See Figure 4 for an overview of the participating teachers, all of whom were female.

At the start of the user evaluation, each teacher was taught how to use the teachertool to control the light-objects. Furthermore, we told them that they could choose for which purpose and at what moments of the day they would use FireFlies, although we encouraged them to use it regularly, preferably at least once every day. We recorded $1 \mathrm{hr}$ of video each week of every teacher using FireFlies. This 1-hr time slot was selected to ensure that a variety of observable activities (e.g., whole-class teaching, independent work, and group instructions) would be captured while also ensuring a sufficient but manageable amount of data for video analysis. In addition, we conducted two semistructured interviews with each teacher-once in the 3rd week and once in the final week of the user evaluation.

The weekly 1-hr videos were recorded by a pocket-size camera, mounted on a small tabletop camera stand. In each classroom, the camera was positioned on a closet that was at least $1.5 \mathrm{~m}$ high, out of the children's reach, in the back or at the side of the classroom. The teachers knew when they were being recorded. Despite the small size and unobtrusive location of the camera, this could may have encouraged them to use FireFlies more often than they normally would (also referred to as the "Hawthorne effect"; Jones, 1992). During two of the 12 interviews, the teacher made a remark about the camera when discussing a particular event that had occurred while the camera was running. For example, P5 mentioned (translated from Dutch), "I used it sometimes to indicate which children could go home, but I was already a little late, this happened

FIGURE 4. Overview of the teachers participating in the FireFlies user study.

\begin{tabular}{llccccccc}
\hline Teacher & Appointment & Age & $\begin{array}{c}\text { Teaching } \\
\text { Experience } \\
\text { in Years }\end{array}$ & School & Class & $\begin{array}{c}\text { No. of } \\
\text { Students }\end{array}$ & $\begin{array}{c}\text { Grade } \\
\text { Student } \\
\text { Age }\end{array}$ \\
\hline P1 & Full-time & 26 & 3 & A & 1 & 25 & 4 & 7 to 8 \\
P2 & Full-time & 24 & 4 & A & 2 & 27 & 5 & 8 to 9 \\
P3 & Part-time & 51 & 23 & B & 3 & 27 & 3 & 6 to 7 \\
P4 & Part-time & 26 & 3 & B & 3 & 27 & 3 & 6 to 7 \\
P5 & Part-time & 46 & 16 & B & 4 & 23 & 4 & 7 to 8 \\
P6 & Part-time & 54 & 32 & B & 4 & 23 & 4 & 7 to 8 \\
\hline
\end{tabular}


today, so I pressed the buttons too quickly ... f for you to clearly see the effect (in the video)." The teacher in this example was clearly aware of the camera. Because the camera's presence was mentioned only two times in the interviews, we believe that its influence on our findings is minor. We further discuss this in Section 6.2.

\subsection{Indicators of Peripheral Interaction Used}

The aim of the study described in this article is to evaluate how teachers used our peripheral interaction design FireFlies during their everyday routines. In particular, we are interested in evaluating if their physical interactions with the teacher-tool shifted to their periphery of attention. We therefore focused our evaluation on events or behaviors that may indicate peripheral interaction with the teacher-tool. Based on theories of divided attention (summarized in Figure 1), we have specified a number of observable potential indicators for peripheral interaction, which we used in our study. These indicators are listed next. Through our study, we aim to explore the extent to which these indicators may be suitable to assess peripheral interaction-on their own, in combination with each other, or in combination with qualitative data such as interviews and informal observations.

- Frequency of interactions, to provide initial insight into the extent to which teachers were able to use FireFlies during their everyday routines. The more interactions teachers are able and willing to perform during real teaching activities, the more likely it seems that these interactions are performed as part of their everyday routines. This measure therefore does not indicate if interactions actually took place in the periphery of attention; it only provides insight into the potential integration of interactions in the teachers' everyday routines.

- Duration of interactions, as a potential indicator for the automaticity of an activity and the extent to which it interferes with a central activity. Duration is a commonly used measure in evaluations of "microinteractions" (Ashbrook, 2010), a field related to peripheral interaction. An interaction of short duration, microinteractions in particular are defined to last no longer than $4 \mathrm{~s}$ and is expected to offer minimal disruption of the main activity, therefore more easily become part of everyday routines.

- Interacting during other tasks. As shown in Figure 1, we see the center of attention as the one activity to which most mental resources are allocated and the periphery as all other potential activities. Activities can thus be performed in the periphery of attention when another activity is performed simultaneously, which requires more mental resources. We therefore evaluated whether teachers interacted with the teacher-tool while performing other tasks, indicated by visual focus and concurrent activities.

- Visual focus, assessing the extent to which teachers are looking at the FireFlies teacher-tool during interaction to evaluate their focus of attention. Visual focus is hypothesized in literature on eye-tracking in HCI (Poole \& Ball, 2006) to indicate a person's focus of attention when using a visual display. The FireFlies teacher-tool being used while looking at something else may indicate that the 
teacher is performing two tasks at once. This, according to our understanding of the center and periphery of attention illustrated in Figure 1, can be a potential indicator that one of the two activities is being performed in the periphery of attention.

- Concurrent activities, assessing whether teachers are performing other activities while interacting with the FireFlies teacher-tool. Observing teachers performing a second activity while interacting with the FireFlies teacher-tool can potentially indicate that a central and a peripheral activity are being performed simultaneously.

\subsection{Data Analysis Procedure}

In this article, we discuss the results of both the video analysis and interviews regarding the teacher's physical interactions with the teacher-tool. Interview findings about the other elements of FireFlies are presented in Bakker et al. (2013). In the analysis of the interview data, we aimed to gain insight into how and when the teachers interacted with the teacher-tool and the extent to which they felt this fit in their everyday routines. The 1-hr videos we recorded during the study were used in a detailed analysis of the teacher's physical interactions with the teacher-tool and the extent to which these took place in the periphery of attention. The videos were observed by the first author, and all moments at which a teacher physically interacted with the teachertool were selected. The beginning and end of each interaction was marked in order to identify its duration of interaction. The interactions were interpreted to start when the teacher grabbed or touched the teacher-tool, and the end of an interaction was marked when the teacher moved her hands away from the tool. In cases where the teacher was holding the teacher-tool in her hand continuously-for example, when walking around-we marked the start of the interaction when the teacher reached either for the slider, a name-bead or the button "everyone." In this case, the end of an interaction was interpreted as the moment that the hand with which the teacher interacted with the tool was moved away from the device. This entails that the interactions ranged from selecting a single name to setting a number of light-objects to one color and various lights to another color.

In total, 497 interactions were found in the video data (see Figure 5). As evident from Figure 5, we were not able to record a video of each teacher in every week of the study. This was caused by absence of teachers, national holidays, irregular school schedules, and sometimes the positioning of the camera.

To gain more detailed insight from the data, a coding scheme was constructed based on the earlier described potential indicators for peripheral interaction. This coding scheme included three behavioral categories, each consisting of a number of instances of behavior (see Figure 6). For each interaction, one instance of each category was assigned to the interaction. In other words, each interaction was identified by the observer as a certain interaction type, performed with a certain degree of visual focus as well as concurrent activities.

To assess the reliability of the coding scheme, a second observer coded 55 of the 497 recorded interactions from different weeks of the study. To determine the extent 
FIGURE 5. The number of interactions with the teacher-tool, found in each 1-hr video, recorded every week of each participating teacher, as well as the weeks in which no video was captured.

\begin{tabular}{lcrrrrrr}
\hline & \multicolumn{7}{c}{ Week } \\
\cline { 2 - 6 } Teacher & 1 & 2 & 3 & 4 & 5 & 6 & Total \\
\hline P1 & 18 & 22 & $\mathrm{x}$ & 5 & 17 & $\mathrm{x}$ & 62 \\
P2 & 49 & 7 & 19 & $\mathrm{x}$ & $\mathrm{x}$ & 14 & 89 \\
P3 & 51 & 8 & 26 & $\mathrm{x}$ & 35 & 13 & 133 \\
P4 & 10 & $\mathrm{x}$ & 13 & 9 & 14 & 8 & 54 \\
P5 & 15 & 14 & $\mathrm{x}$ & 17 & $\mathrm{x}$ & 30 & 76 \\
P6 & $\mathrm{x}$ & 27 & 10 & 6 & 12 & 28 & 83 \\
Total & 143 & 78 & 68 & 37 & 78 & 93 & 497 \\
\hline
\end{tabular}

Note. Weeks in which no video was captured are indicated with "x."

FIGURE 6. Coding scheme used for video analysis and the level of agreement (Kappa Coefficient $\mathrm{K}$ ) between the two coders, in each category of the coding scheme.

\begin{tabular}{lll}
\hline Category & \multicolumn{1}{c}{ Instance of Behavior } & $\mathrm{K}$ \\
\hline $\begin{array}{l}\text { Interaction type } \\
\text { (What is the teacher doing with } \\
\text { the teacher-tool?) }\end{array}$ & $\begin{array}{l}\text { Selecting 1 name or 1 color or button "everyone" } \\
\text { Selecting 1 color and 1 name or button "everyone" }\end{array}$ & 0.77 \\
& Selecting multiple colors and/or multiple names or buttons \\
Unclear interaction type & 0.68 \\
Visual focus & Constantly & \\
(How much of the interaction & Most of the time \\
time is the teacher looking at the & Most of the time not \\
teacher-tool?) & Never & 0.43 \\
& Unclear visual focus \\
Concurrent activities & In between two other tasks \\
(Is the interaction performed & During another task \\
during another task?) & Interrupts another task \\
& Unclear concurrent activities \\
\hline
\end{tabular}

to which the two coders agreed, we calculated Cohen's Kappa statistic, which provides the agreement between coders as a number between 0 and 1 ( 0 meaning no agreement and 1 meaning perfect agreement; Siegel \& Castellan, 1988). Figure 6 presents the Kappa Coefficients for each category of our coding scheme. According to Landis and Koch (1977), the values we found can be interpreted as substantial agreement in the categories interaction type and visual focus and moderate agreement in the category concurrent activities.

\section{FINDINGS AND DISCUSSION OF FIREFLIES}

This section presents and discusses our findings regarding the three earlier presented potential indicators for peripheral interaction: frequency of interactions, duration of 
interactions, and interacting during other tasks. We start, however, by explaining how the teachers chose to work with FireFlies in their classrooms (also see Bakker et al., 2013).

\title{
6.1. How FireFlies Was Used
}

FireFlies is an open-ended design; the teachers were asked to choose how and when they would use it. To give an impression of how FireFlies was used, we now describe an example scenario of use, taken from the interview data. As each teacher could choose her own way of using FireFlies, this scenario is not exhaustive of all ways in which FireFlies was used.

\begin{abstract}
School has just started; the children take their seats in the classroom. After the teacher finished explaining the mathematics lesson to the class, she makes all lightobjects red and the children start working on their assignments in silence. The teacher takes a seat at her desk and looks into the classroom. She makes one of the light-objects blue and three others yellow. Following, three children pick up their (yellow) light-object, walk to the computer-corner, and start working on this week's computer exercise. One child picks up his (blue) light-object and walks to the teacher's desk for a short knowledge test. When the test is finished, the teacher turns this child's light-object back to red and makes one other blue. While the child walks back to his desk, the teacher sees that the group in the back of the class is working very well. She decides to give them a compliment by making their light-objects green.
\end{abstract}

All teachers chose to link each color to a specific rule or event. In two classrooms, the meaning of the different colors was decided by discussing it with the children on the first day of the experiment. In two other classrooms, the teachers decided on this before the experiment started. In two of the classrooms, red and green lights were used to indicate whether or not the children were allowed to discuss; red meant "work in silence" and green meant "you are allowed to discuss." In the other two classes, the teachers used a green light to give individual children a silent compliment. In one class, red was used to give individual children a warning when they were not working properly. In three classes, a blue light was used to call children to the teacher's desk, as illustrated in the previous example. Yellow was used in two classrooms to tell which children were allowed to work on the computer. See Figure 7 for an impression of how FireFlies was used in the participating classrooms.

In all four classrooms, FireFlies was used every day of the user evaluation, as indicated by the participating teachers. Although the teachers were allowed to change the meaning they had connected to the different colors whenever they wanted, this happened only in one classroom for one of the colors in the first week of the study. The teachers indicated that they preferred to use the colors consistently for the same purpose, such the meaning of each color was easily remembered and no confusion was caused. Although the meaning of each color was written on the whiteboard on the first day of the study in most classrooms, this information was quickly redundant 
FIGURE 7. Picture taken during the deployment of FireFlies: The children are working independently, many of them have received a compliment (green light) and some were allowed to work on the computer (yellow light).

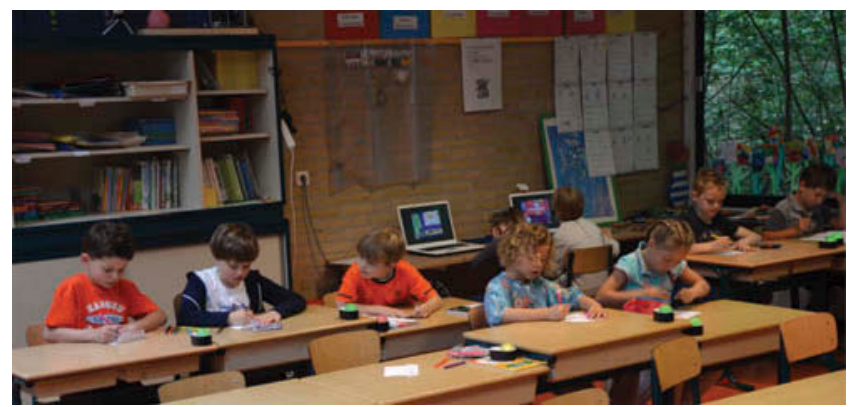

and in some cases removed from the board. See Bakker et al. (2013) for an extensive qualitative overview of how FireFlies was used as a communication technology in the four participating classrooms.

As a result of viewing the videos captured during the user evaluation, we observed that the teachers interacted with the teacher-tool during several different classroom situations. The teachers often used the teacher-tool during whole-class instructions or while giving individual instructions to a (small group of) child(ren). Furthermore, we observed the teachers interacting with the tool while observing how the children were doing and during administrative tasks at their desks. The teachers were mostly interacting with the teacher-tool while they were sitting at their desks or at tables in front of the classroom. In these cases, the tool was lying on the table or on the teacher's lap. To interact with the teacher-tool, the teachers would either pick it up or manipulate it while it was lying on the table. A number of teachers carried the teacher-tool around the classroom, for example, while walking around to help children. In these cases, the teachers usually held it in their hands rather than clipped it to their clothes, as they found it easier to interact with the tool that way. See Figure 8 for a picture of a teacher using the teacher-tool during the user evaluation.

\subsection{Frequency of Observed Interactions with FireFlies}

To gain insight into the extent to which interactions with the teacher-tool fit in the teacher's everyday routine, we counted the number of interactions in each video we recorded (see Figure 5). As evident from Figure 5, the number of interactions per video differed considerably. Given the open-ended nature of the design, teachers could choose how often they used FireFlies, and clearly it was more often used in some lessons compared to others. The number of captured interactions also seems influenced by other factors however. Teachers were not always in sight of the camera when they interacted with the teacher-tool, for example, when walking around the room. Also, the nature of some lessons engendered more interactions compared to other lessons. For example, the video of teacher P2 was recorded each week during a 
FIGURE 8. Picture taken during the deployment of FireFlies: The teacher interacts with the teacher-tool while she is giving instructions to a small group of children.

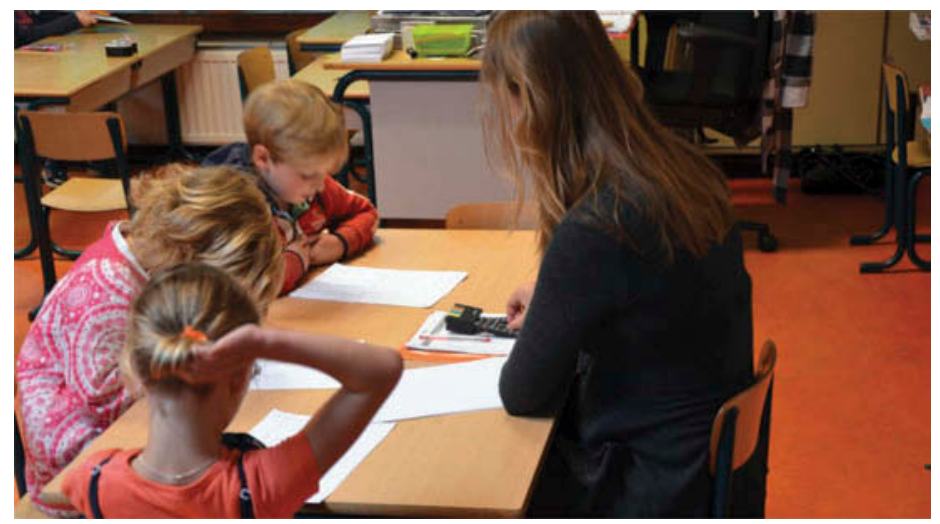

mathematics lesson. During one lesson, P2 called each child to her desk individually for a quick knowledge test, whereas in two other lessons, she called a group of children to her desk to work with them during the entire lesson. As P2 used FireFlies to call children to her desk, she interacted with the teacher-tool much more often in the first case than in the second. It is therefore important to note that the numbers in Figure 5 should not be used to interpret longitudinal effects of the success or acceptance of FireFlies over the 6 weeks. Furthermore, it must be taken into account that the teachers knew they were being recorded, which may have encouraged them to use FireFlies more often than they normally would (the Hawthorne effect; Jones, 1992).

Despite these limitations, it is clear from Figure 5 that the teacher-tool was interacted with five to 51 times per hour, in the hours we recorded on video. This means that even in the video with the lowest number of interactions, the teacher operated the tool on average once every $12 \mathrm{~min}$. At the other extreme, a teacher was able to interact with the teacher-tool almost once every minute on average. In some videos, the interactions indeed took place around once every 5 to $10 \mathrm{~min}$. In other videos, the interactions were less equally distributed over the recorded hour, but the frequency of interactions was higher in a shorter fragment of the recording. As all interactions took place during regular lessons, the frequency of recorded interactions seems to indicate that the teacher-tool could be used during the everyday routine of the teacher.

\subsection{Duration of Observed Interactions with FireFlies}

As another potential indicator for the extent to which the teachers were able to interact with the teacher-tool as part of their everyday routine, we determined the duration of each interaction we captured on video. The graph in Figure 9 shows the average interaction duration in each video we captured during the experiment. As evident from this graph, the average interaction duration did not clearly increase or decrease over the course of the evaluation for any of the participants. 
FIGURE 9. The average duration of interactions of each participant, in each week of the study.

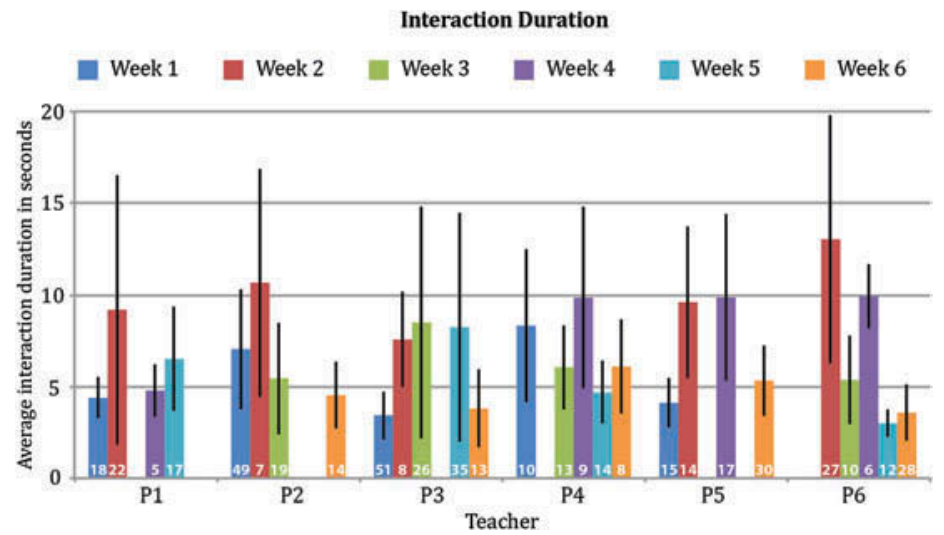

Note. The white numbers reveal, for each participant, the numbers of interactions captured in each week.

FIGURE 10. The average duration of interactions of each interaction type, for each participant.

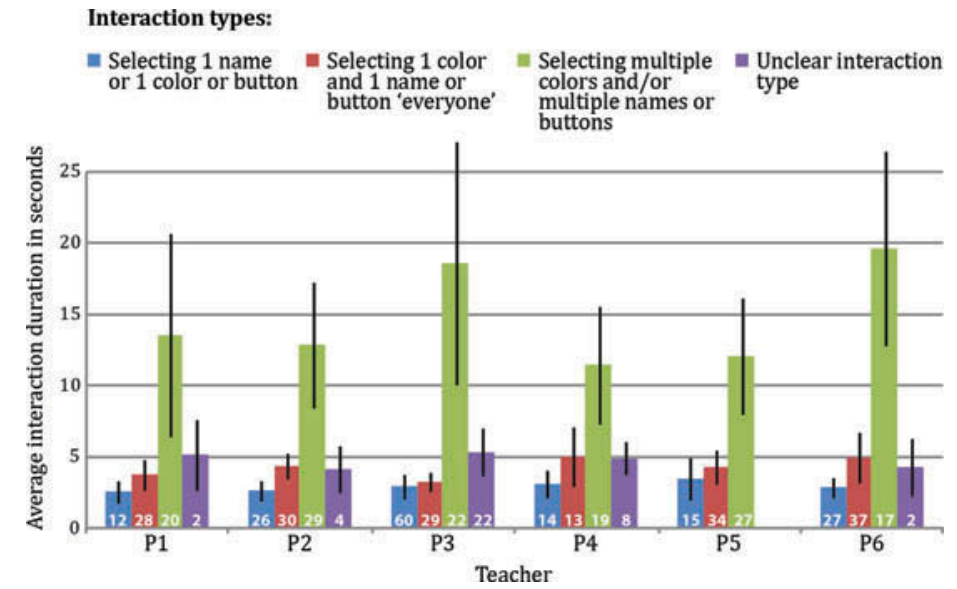

Note. The white numbers reveal, for each participant, the numbers of interactions captured of each type.

Clearly, the interaction duration largely depends on the type of interaction the teacher is performing. For example, selecting a single name should take less time than selecting a color and three names. We therefore included the category interaction type in our coding scheme (see Figure 6). The graph in Figure 10 shows the types of interactions that were coded, mapped to the average interaction duration. This graph shows that, as expected, the interactions that involved only one or two moves required less time compared to the interactions that required selecting multiple colors or names. Although not revealed in a graph, no clear increase or decrease in interaction duration over the course of the experiment was apparent when separating the different interaction types. 
Figure 10 furthermore reveals that, on average, the interactions that required only one or two moves, took less than $5 \mathrm{~s}$. Additional to our earlier finding that some teachers were able to frequently interact with the teacher-tool, we can now conclude that also many of the captured interactions were rather short in duration. Interactions of short duration are expected to offer minimal interruption to the main activity (Ashbrook, 2010). Shorter interactions thus seem more likely to become embedded into the everyday routine.

\subsection{Interacting With FireFlies During Other Tasks}

As discussed in Section 2 and illustrated in Figure 1, our understanding of the center and periphery of attention is grounded in divided attention theory (Kahneman, 1973). Therefore, we see the one activity to which most mental resources are currently allocated as the center of attention. The periphery of attention then consists of all other potential activities. Peripheral interaction thus takes place only when two activities are being performed simultaneously. We therefore evaluated whether teachers interacted with the teacher-tool while performing other tasks.

An observable phenomenon that may indicate if the teacher is doing another task is whether or not she is looking at the teacher-tool during interaction. As it was impossible to use sophisticated eye-tracking technology (Poole \& Ball, 2006) in the classroom setting, we assessed the teachers' visual focus in our video coding scheme (see Figure 6). The code constantly was used when the teacher did not take her eyes off the tool during the interaction. Most of the time indicated that the teacher at one or more moments looked away from the tool. Most of the time not was used to code interactions during which the teacher only sometimes looked at the device, and never indicated that the teacher never looked at it. Figure 11 shows the number of interactions captured of each level of visual focus. Figure 12 presents the results for this category for each participant as a function of the average duration of interactions.

As evident from Figure 11, during the majority of the recorded interactions of all teachers, most of the time they were looking at the teacher-tool. In a number of cases, the teachers were not looking at it most of the time, and we even observed three

FIGURE 11. The total number of interactions of each level of visual focus, for each participant.

\begin{tabular}{lrrrrrrr}
\hline & \multicolumn{7}{c}{ Teacher } \\
\cline { 2 - 6 } Visual Focus & P1 & P2 & P3 & P4 & P5 & P6 & Total \\
\hline Constantly & 7 & 31 & 40 & 8 & 25 & 16 & 127 \\
Most of the time & 38 & 46 & 78 & 35 & 41 & 59 & 297 \\
Most of the time not & 16 & 6 & 10 & 10 & 5 & 6 & 53 \\
Never & 1 & 1 & 1 & 0 & 0 & 0 & 3 \\
Unclear visual focus & 0 & 5 & 4 & 1 & 5 & 2 & 17 \\
Total & 62 & 89 & 133 & 54 & 76 & 83 & 497 \\
\hline
\end{tabular}


FIGURE 12. For each participant, the average duration of interactions of each level of visual focus, describing how much of the interaction time the teacher is looking at the teacher-tool.

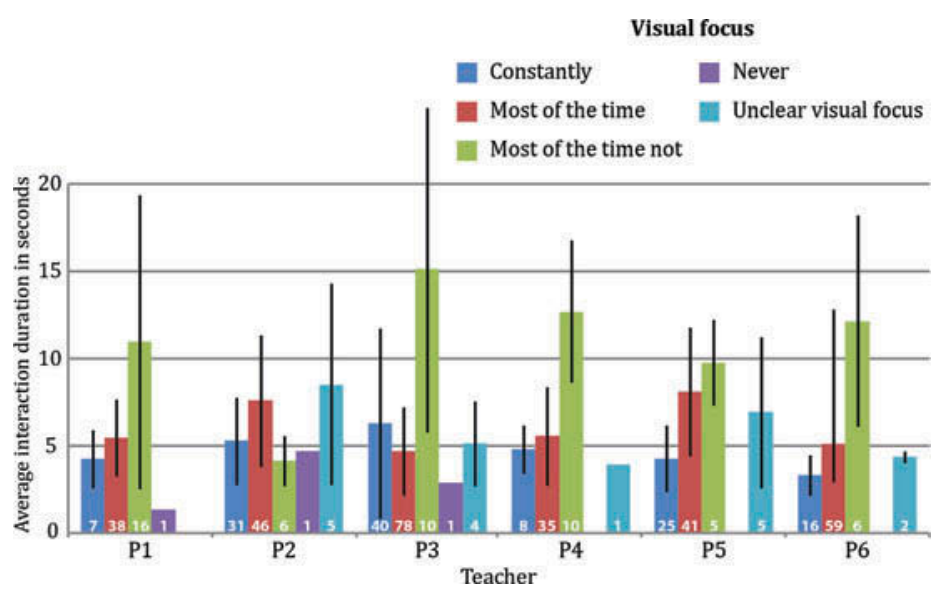

Note. The white numbers reveal, for each participant, the numbers of interactions captured of each level of visual focus.

cases in which the teacher never looked at the teacher-tool during interaction. This also became clear in the interviews. P2, for example, mentioned,

\begin{abstract}
When I know "now they all have to be green or I will turn them all off," then I can do it immediately there (without looking at the teacher-tool, while it is attached to the teacher's belt), but if I am really looking around or working here (at the teacher's desk), then I take it (the teacher-tool) in my hand so I can select individual children.
\end{abstract}

Figure 12 indicates that, for many participants, the interactions in which they were most of the time not looking at the tool on average required the most time. The interactions in which the teachers were constantly looking at the tool on average had the shortest duration. Overall, we must conclude that the teachers were able to interact with the teacher-tool without constantly looking at it, even though these interactions required more time on average.

To gain additional insight into whether the interactions with the teacher-tool took place during other tasks, we included the category concurrent activities in our coding scheme (see Figure 6). In this category, we observed if the teacher was clearly involved in another task, which continued after the end of the interaction, for example, if a teacher was giving instructions to the class or to an individual child while interacting with the teacher-tool. If this was not the case-for example, when the teacher interacted with the tool in between two individual instruction sessions- the code in between two other tasks was used. When the teacher's primary task was the same before and after the interaction, it was interpreted whether the interaction clearly interrupted and disturbed this primary task, in which case the code interrupts another 
FIGURE 13. The total number of interactions of each instance of concurrent activities, for each participant.

\begin{tabular}{lrrrrrrr}
\hline & \multicolumn{7}{c}{ Teacher } \\
\cline { 2 - 6 } Instance of Concurrent Activities & P1 & P2 & P3 & P4 & P5 & P6 & Total \\
\hline In between two tasks & 14 & 41 & 8 & 11 & 32 & 31 & 137 \\
During a task & 48 & 45 & 107 & 33 & 41 & 51 & 325 \\
Interrupts a task & 0 & 0 & 11 & 9 & 2 & 1 & 23 \\
Unclear & 0 & 3 & 7 & 1 & 1 & 0 & 12 \\
Total & 62 & 89 & 133 & 54 & 76 & 83 & 497 \\
\hline
\end{tabular}

task was used-for example, when the teacher stopped her instructions to the class in order to use the teacher-tool. If the interaction did not seem to disturb the primary task, it was coded as during another task. As evident from the Kappa coefficients in Figure 6, the two coders came to a moderate agreement only in the category concurrent activities, whereas a substantial agreement was reached in the other two categories. Both coders found the teachers' concurrent activities most difficult to interpret from the videos. The number of interactions of each of these instances is listed in Figure 13.

As evident from Figure 13, a clear majority of the interactions of all teachers were performed during another ongoing task, such as while giving individual instructions. The interactions that were performed in between two tasks mostly seemed to take place in between two instruction sessions. In these cases, a child was walking back to his desk and the teacher used the teacher-tool to turn this child's light off and to make another child's light blue to call him to her desk. The fact that these interactions happened in between two tasks therefore does not seem to indicate that they were too demanding to be performed during another task but simply that the situation in which they occurred was only suited for in-between interactions. Despite the moderate agreement between coders, the differences between the overall numbers in Figure 12 seem large enough to at least conclude that many of the teachers' interactions occurred during other tasks.

As previously mentioned, (inter)actions are assumed to take place in the periphery of attention when another task, which requires more mental resources, is being performed simultaneously. The results in both the categories visual focus and concurrent activities seem to reveal that indeed the teachers were in many cases interacting with the teacher-tool while another task was ongoing. Figure 14 maps the results in these two categories to each other. As evident from Figure 14, most of the cases in which the teachers were not constantly looking at the teacher tool during interaction occurred when the interaction took place during another primary task. According to our understanding of the periphery of attention, we can therefore assume that in these cases either the interaction with the FireFlies teacher-tool or the teaching-related task was in the teacher's periphery of attention. 
FIGURE 14. The total number of interactions of each instance of concurrent activities, mapped to each level of visual focus, for all participant combined.

\begin{tabular}{lccccccr}
\hline & \multicolumn{5}{c}{ Level of Visual Focus } \\
\cline { 2 - 6 } $\begin{array}{l}\text { Instance of } \\
\text { Concurrent Activities }\end{array}$ & Constantly & $\begin{array}{c}\text { Most of } \\
\text { the Time }\end{array}$ & $\begin{array}{c}\text { Most of the } \\
\text { Time Not }\end{array}$ & Never & Unclear & Total \\
\hline In between two tasks & 42 & 86 & 7 & 0 & 2 & 137 \\
During a task & 69 & 195 & 45 & 3 & 13 & 325 \\
Interrupts a task & 9 & 12 & 1 & 0 & 1 & 23 \\
Unclear & 7 & 4 & 0 & 0 & 1 & 12 \\
Total & 127 & 297 & 53 & 3 & 17 & 497 \\
\hline
\end{tabular}

\subsection{An Observed Example of Peripheral Interaction}

As became clear from the earlier discussion of video observation results, several interactions with the teacher-tool seem to comply with indicators of peripheral interaction, namely, frequency of use, duration of interaction, and the possibility of being performed during another task. Although promising, these data do not prove that any of the interactions took place in the periphery of attention according to our model presented in Figure 1. When looking at the videos we recorded, however, we did observe situations in which we believe that the interaction with the teacher-tool indeed shifted to the teacher's periphery of attention, particularly in the 5th and 6th week of the study. We illustrate this by describing a specific example, taken from the video recorded in Week 5 of teacher P4. The situation in this particular part of the video is as follows:

P4's class is working on a writing exercise. At the same time at the instruction table in front of the room, P4 is doing a reading exercise with four children: they simultaneously read words aloud. During this reading exercise, the teacher is also paying attention to the rest of the class: she observes if they are working well, and gives compliments or warnings using green or red lights. While interacting with the teacher-tool, teacher P4 sometimes keeps reading the words of the readingexercise aloud.

In this situation, the teacher has three activities: (a) the reading exercise, (b) observing the class, and (c) interacting with the teacher-tool. Apart from these activities, she can potentially also do other activities, such as helping a child with his writing exercise, discussing an example of this exercise with the class, giving a child more reading material to practice, looking at the clock, or checking her e-mail. These latter activities might also be on her mind, although they are not performed. To discuss the teacher's activities in terms of whether they are central or peripheral, we present a hypothetical division of mental resources at four moments in the video connected to the preceding example, recorded of teacher $\mathrm{P} 4$ in a real classroom situation during our user evaluation (see Figure 15). 
FIGURE 15. Four screen shots from the video recorded of teacher P4 in the fifth week of the study, while the FireFlies teacher-tool is on her lap, and for each screen shot the possible division of mental resources (also see Figure 1) over the following (potential) activities: reading exercise (read), observing the class (observe), interacting with teacher-tool (interact), helping with writing exercise (help), discussing writing exercise (discuss), giving practice material (give), looking at the clock (look), and checking email (check).
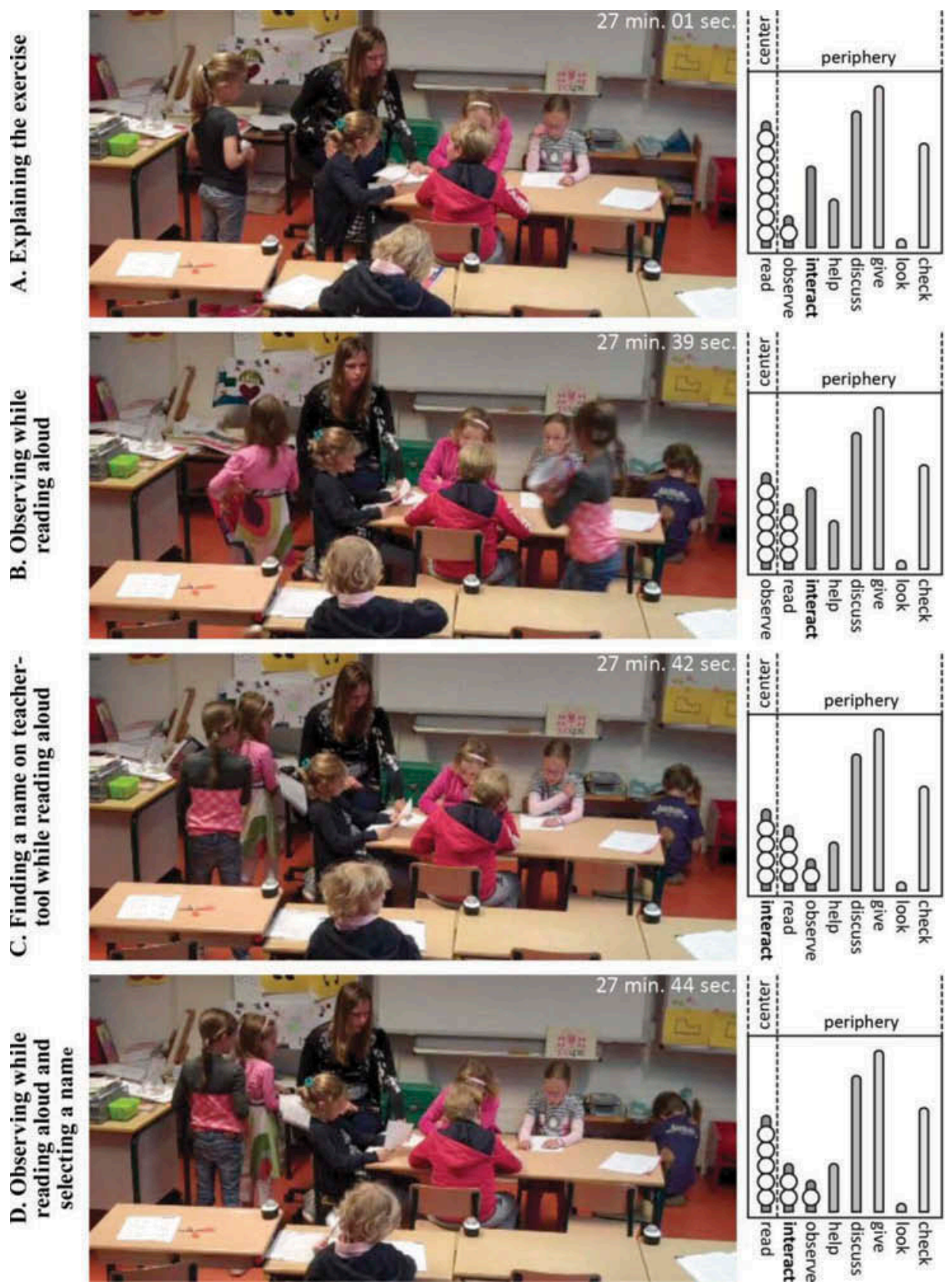
Figure $15 \mathrm{~A}$ shows the moment at which the teacher is explaining the reading exercise to the group of four children. Although this activity likely requires most of her mental resources and is thus in her center of attention, she is probably also keeping an eye on the class in her periphery of attention. At this moment she is not interacting with the teacher-tool, so this potential activity is also in the periphery. Figure 15B shows a later moment at which the teacher and four children are reading words aloud. The teacher is simultaneously looking into the room to observe the children, which might cause the reading exercise to shift to her periphery of attention. The next moment (Figure 15C), the teacher looks for a name on the teacher-tool to give a compliment while still reading aloud. This interaction with the teacher-tool is likely performed in the center of attention, causing other activities to shift to the periphery. A moment later (Figure 15D), the teacher is still reading aloud and looks at the list of words of the reading-exercise while squeezing a bead to give a compliment. Interaction with the teacher-tool is now likely in the periphery of attention, whereas the reading exercise is back in the center.

In this example, the reading-exercise is clearly the teacher's main activity and will most of the time be in her center of attention. Observing the children seems a secondary task, which is most often in the periphery of attention but may shift to the center when fewer resources are required for the reading exercise. Interacting with the teacher-tool also seems a secondary task, which may be in the center of attention when required (e.g., to find the right name) but may also be performed in the periphery (e.g., when selecting a name).

In the interviews, teachers also mentioned that interacting with teacher-tool required minimal mental resources and was possible while giving instructions to a small group of children. P6, for example, mentioned, "In the situation in which we currently use it (giving instructions to a small group while the rest of the class works independently), this (the teacher-tool) requires minimal concentration."

From this observed example it seems likely that P4 interacted with the teachertool in her periphery of attention. In the interviews, the teachers stated that one of the main advantages of FireFlies was that it enabled them to communicate messages (e.g., compliments) in silence as well as while working on another task. For example, P4 mentioned, "When I work with groups, while I sit at the instruction table (with a group of children), I can send children a message without saying anything and without disturbing my group." It therefore seems that it was relevant to the teachers to interact with the tool during other activities, which may have realized the interaction to shift to the periphery.

\section{DISCUSSION OF PERIPHERAL INTERACTION}

The aim of the study presented in this article was to explore a longitudinal field study approach to evaluate whether people could physically interact with a dedicated device in their periphery of attention. We applied this approach in a study with our peripheral interaction design FireFlies. The results of formal and informal video analyses seem to indicate that indeed peripheral interaction was at moments feasible 
with FireFlies. In this section we discuss the insights we gained regarding peripheral interaction in general. The following section addresses the evaluation approach.

\subsection{Peripheral Interaction and the Everyday Routine}

The main aim of peripheral interaction is to enable interactive systems to fluently blend in with the user's everyday routine. In our study with FireFlies, we conducted interviews with the teachers who used the design in their classrooms. One of the discussed topics was the extent to which teachers saw these interactions as a part of their everyday routines. These discussions revealed interesting insights in the process of embedding interactions into one's everyday routine.

In the interviews, several teachers mentioned that although they found the interactions with the teacher-tool quick and easy, they needed to consciously think about using it, particularly in the beginning of the study. One teacher mentioned, "I notice that, if I have not consciously thought about it for a while, sometimes I am calling children to my desk verbally and then think 'I could have done this with the lightobject." All teachers used FireFlies to try to replace previous ways of working, such as giving turns and compliments verbally. When they wanted to give a child a turn or compliment, they therefore automatically did this verbally without consciously thinking about it. In the 6th week of the study, however, most teachers indicated that using FireFlies had in many cases become an automatic or routine activity. Due to absence of a teacher, one final interview took place in the week after the study, when FireFlies was no longer present. This teacher mentioned, "I sometimes think 'where are my light-objects,' but then I realize they aren't here anymore.” Other teachers indicated in the final interview that although they had to get accustomed to using FireFlies instead of verbal messages, they now have to get used to verbal messages again. This seems to indicate that, at certain moments, FireFlies was to some extent used on a routine basis.

An interesting insight here is that being able to perform an interaction quickly and easily, during another task, is not the only precondition for the interaction to become an automated part of the everyday routine. Clearly, the cognitive action (deciding to use the teacher-tool for a certain purpose) that precedes the physical interaction (actually interacting with it) should ideally be automated as well. This relates to theory on habituation (Aarts \& Dijksterhuis, 2000; Wood \& Neal, 2007), which states that habituated actions are strongly associated with their goals; whenever the goal is activated, the associated action will automatically and subconsciously be initiated. When an interaction is replacing an activity that is habituated, it takes time and experience to associate the goal (e.g., giving a child a turn) to the new (inter)action. It is clearly not only required to learn to work with the new interactive system but also needed to "unlearn" the known activity. Based on the statements our participants made in the interviews, it seems that in the case of FireFlies, using it for 6 weeks was enough for this habituation to happen. Interestingly, however, the quantitative results discussed earlier do not seem to clearly show more indicators for peripheral interaction toward the end of the user study. We believe this may have been a result of the duration of the study, as is further discussed in Section 8. 


\subsection{Shifts Between the Center and Periphery of Attention}

Peripheral interaction describes interaction with technology, which may take place in the periphery of attention but which may also shift to the center of attention when relevant for or desired by the user. Therefore, such interactions do not unnecessarily disrupt or burden users when performed in the periphery while also enabling users to fully engage with or focus on these interactions when performed in the center of attention. Although the focus of the study presented in this article has been on finding evidence for interactions taking place in the periphery, shifts between the center and the periphery of attention are a vital part of peripheral interaction.

When analyzing if the teachers' interactions with the FireFlies teacher-tool took place in the periphery of attention, we realized that it was useful to divide these interactions into smaller stages of action. For example, in Figure 15 we distinguished finding a name on the tool from selecting this name and concluded that this particular interaction shifted from the center to the periphery at the latter stage. In addition, we realized that deciding to use the teacher-tool for a certain purpose can take place in either the center or the periphery of attention. It may be the case, for example, that a teacher peripherally decides to use FireFlies to give a child a compliment, then searches for the right name in the center of attention, and subsequently selects this name in the periphery. Clearly a single interaction can shift from center to periphery and back frequently and in between or during different stages of interaction. This seems important for the evaluation of peripheral interaction: To observe peripheral interaction, evaluators may need to look in detail at separate stages of interaction rather than only gaining an overall image of a period in which a peripheral interaction design was used.

\subsection{Peripheral Interaction in a Primary School Context}

The work presented in this article evaluates peripheral interaction in a primary school context. The focus of our research was on whether our design could be interacted with in the periphery of attention rather than on the potential benefits of FireFlies in the educational context. We chose this context because we believe that primary school teachers, who have busy everyday routines consisting of numerous small tasks, can benefit from technologies that support their secondary tasks. In the interviews, the teachers indicated that they could easily operate the teacher-tool during other activities, for example, while giving instructions to a small group of children. They also indicated that this was useful as it enabled them to communicate to the class in silence (e.g., to give a compliment or warning), without having to interrupt the instruction session. This enabled them to stimulate or correct the children at moments that are normally not suitable for such communication. Although this was not the focus of our study, it seems that these kinds of peripheral interaction designs are suitable for the primary school context. We therefore believe that our study provides preliminary support for Börner et al.'s (2011) vision that peripheral interactive systems are suitable for the educational context. 


\section{DISCUSSION OF THE EVALUATION APPROACH}

The study presented in this article aimed to explore a longitudinal field study approach to evaluate peripheral interaction. Although related work is available on the evaluation of technologies aimed to employ the periphery of attention, particularly evaluations of physical peripheral interaction are scarcely reported. A few examples (Edge \& Blackwell, 2009; Hausen et al., 2012) report interesting evaluations based on informal, anecdotal evidence. Because we aimed for a more structured and longitudinal approach, we now discuss the insights we gained regarding this strategy.

\subsection{Assessing Peripheral Interaction}

In the video analysis of our study with FireFlies, all captured interactions with the teacher-tool were marked. These data were then used to assess whether potential indicators for peripheral interaction were present (i.e., frequency of interactions, duration of interactions, and interacting during other activities). Because no previous formal video analysis on physical peripheral interaction is known, each of these indicators was exploratory. As indicated, none of these indicators were intended to provide conclusive evidence for interactions taking place in the periphery of attention. Rather these indicators were meant to reveal the potential presence of characteristics of peripheral interaction.

One of these indicators, the duration of interaction was taken into account because decreasing interaction duration over time could indicate an increased level of automaticity over the weeks. Furthermore, measuring interaction duration is a common evaluation strategy for microinteractions (Ashbrook, 2010; Wolf et al., 2011), an interaction style related to peripheral interaction, as interactions of a duration shorter than 4 min are expected to offer minimal interruption to the main activity. The average interaction duration did not clearly decrease during the course of the evaluation for any of the participants, however (see Figure 9). Also, when separating the different types of interactions, no apparent decrease in interaction duration was found. As an additional indicator for peripheral interaction, we coded the extent to which the teachers were looking at the teacher-tool during interaction. Of interest, Figure 12 shows that interactions that took place when the teacher was most of the time not looking at the teacher-tool, required most time. This is an understandable finding, as these interactions likely occurred when she was doing something else in the meantime, as also evident from Figure 14. For example, P5 used the teacher-tool at the start of a lesson to allow a number of children to discuss. She did that while looking into the room to see which children could discuss but also while explaining which exercise the children had to do. Interacting with the teacher-tool may therefore have taken more time compared to similar interactions that are not performed during another task. When performing two activities at the same time (i.e., concurrent multitasking; Salvucci \& Taatgen, 2010), the two activities may be shifting back and forth between the center and periphery of attention, as may have been the case in the previously discussed example and the example presented in Figure 15. The interaction in these examples 
may therefore have been performed in the periphery of attention during parts of their duration, while they were performed in the center of attention during other parts, thus showing indication of peripheral interaction at some moments of these interactions. On the other hand, because such interactions take more than $4 \mathrm{~s}$, they likely also influence the performance of the main, teaching-related, activity. Although short interaction duration, therefore, does not seem to be a conclusive indicator for peripheral interaction on its own, it may be used to indicate short duration of concurrent multitasking and therefore minimal potential distraction from the main activity.

Interacting during other activities was used as another exploratory indicator for peripheral interaction, because peripheral activities are typically performed in parallel with a different main activity, as discussed in Section 2. We therefore evaluated the participants' visual focus and whether concurrent activities were being performed. These measures revealed that indeed participants were, in some cases, able to interact with our teachertool design without constantly looking at it and while performing other activities simultaneously. Although this seems promising, these measures, as anticipated, do not prove that the interactions took place in the periphery of attention. First, what a participant is looking at does not necessarily have to be his or her focus of attention. Second, the measure of concurrent activities — which indicates if an interaction was performed during, between, or as an interruption of another activity — was interpreted by video observers in the study with FireFlies. It can be questioned if an external observer is able to reliably interpret whether an interruption takes place, as this may not be clearly visible. This problem is also revealed in the moderate agreement between coders in the category concurrent activities (see Figure 6). Clearly, the used measures come with limitations.

Despite these limitations, however, the results of the used measures we used in our study with FireFlies have given us the impression that some interactions were performed with minimal visual focus and that the participating teachers were at times interacting with the teacher-tool while performing another task simultaneously. Qualitative observations, such as the one presented in Figure 15, suggest that interactions with the teacher-tool indeed shifted between the teachers' center and periphery of attention. We therefore believe that the coding scheme we used (see Figure 6) was indeed helpful in observing if peripheral interaction with a design is likely feasible.

Although a number of interactions we captured complied with our indicators for peripheral interaction, we also captured several interactions that did not comply with them. Clearly not all interactions with the FireFlies teacher-tool took place in the periphery of the teacher's attention. As previously mentioned, peripheral interaction designs are intended to allow interaction in the periphery of attention without disturbing the primary task, whereas these interactions may also be focused on in the center of attention when this is relevant for or desired by the user. Our evaluation focused mainly on assessing the feasibility of interactions with the teacher-tool to take place in the periphery of attention rather than on interactions shifting to the center of attention. Although some of the measures we used (i.e., visual focus and concurrent activities) provided potential indicators for interactions in the periphery, these measures alone cannot be used to determine the success of the FireFlies design 
for classroom use. To reach the latter goal, qualitative evaluations of the value of the design are needed, both at moments of peripheral use and at moments of central use. As briefly summarized earlier, and more extensively described in Bakker et al. (2013), FireFlies indeed seemed valuable to the teachers, who, for example, were pleased with the possibility of communicating with one child while they were giving instructions to another child. Summarizing, the evaluation strategy applied in the present study seems suitable to identify indicators for peripheral interaction with a design, whereas qualitative findings are essential to assess the value and thus the success of the design.

\subsection{Duration of the Evaluation}

We deployed FireFlies in the participating classroom for 6 weeks, such that there was enough time to get used to it and to integrate it in the everyday routine. In the interviews, teachers reported that interactions with the teacher-tool became more automated over time. Furthermore, informal video observations resulted in examples, such as the one presented in Figure 15, which seem to indicate peripheral interaction with FireFlies. These examples were found in the videos of the last 2 weeks of the study. Qualitative results, therefore, seem to indicate that it was crucial to conduct a long-term study, to observe peripheral interaction development. The formal video observation data, however, do not seem to clearly show longitudinal effects. For example, the duration and frequency of interactions did not clearly change over the course of the study, nor did the number of occurrences of any instance of behavior within our coding scheme. Instead most of these findings varied over the weeks.

We see some potential reasons for the fact that no longitudinal effect was found in the formal video analysis. As mentioned earlier, the user study with FireFlies made us realize that the cognitive action of deciding to use the new technology to reach a certain goal needs to be automated before the interaction can blend into the everyday routine. This seemed to hold particularly when the same goal (e.g., giving a child a compliment) was previously reached through a different activity (e.g., through a verbal message). For example, teachers sometimes habitually gave compliments verbally before realizing they had planned to use FireFlies for this. In the first week of the study, the teachers were probably rather conscious about using FireFlies, as it was newly introduced in their class: A novelty effect (Lippert, 2003) likely occurred. As a result, it seems unlikely that they often "forgot" to use it. Possibly the fact that they knew they were being recorded strengthened this effect. In later weeks, the teachers may have been less conscious about using FireFlies (it was less novel), but as the decision to use it was possibly not habituated, they may often have automatically applied their known method rather than FireFlies. In the last weeks of the study, using FireFlies may have become automated in certain situations, as a result of which the teachers may have used it more often. This could explain why we informally observed indicators for peripheral interaction in the final weeks of the study, whereas a longitudinal effect was not evident from the video analysis. Summarizing, we expect that showing longitudinal effects with FireFlies or other peripheral interaction designs is possible but requires 
evaluations longer than our 6 weeks. As we found indicators of habituations in the 5 th and 6 th week of the study, 10 to 12 weeks seems suitable to find longitudinal effects with the FireFlies design.

\section{CONCLUSIONS}

In this article we have presented a 6 -week evaluation of a dedicated peripheral interaction design in four primary school classrooms. Although FireFlies consisted of several elements, the discussion in this article focused on the teachers' physical interactions with the teacher-tool and the extent to which these interactions shifted to their periphery of attention.

As a result of video analysis, we found that teachers were able to interact with the teacher-tool frequently and that the average duration of these interactions was short. Furthermore, video observation revealed that many physical interactions were being performed without disturbing ongoing tasks and that the teachers did not need to constantly look at the tool to interact with it. Qualitative examples taken from videos recorded in the final weeks of the study seem to indicate that indeed the interaction with the teacher-tool shifted to the periphery of attention at times.

Interviews conducted with the six participating teachers showed us that using FireFlies replaced previous ways of working (e.g., giving turns verbally). This influenced the interaction blending into the everyday routine: The teachers automatically applied their known methods, and deciding to interact with the teacher-tool instead required extra conscious thought in the beginning of the study. It seemed, however, that the decision to use FireFlies became automated toward the end of the study. Longterm deployment of peripheral interaction in the intended context of use was therefore was deemed essential to assess its effects.

This article contributes to existing work in the areas of calm technology, tangible interaction and HCI in general by exploring the field of peripheral interaction, which goes beyond enabling peripheral perception of information but also aims to facilitate physical peripheral interaction. This paper provides initial evidence for the feasibility of physical peripheral interaction by showing how a dedicated interaction design seems usable in the periphery of attention. Moreover, this article presents an approach to the formal evaluation of peripheral interaction in a longitudinal field study, which was applied in the study with FireFlies. This "in-the-wild" approach is increasingly recommended for the evaluation of (peripheral) interactive systems. We therefore believe that this work contributes to HCI literature by providing an example of a formal evaluation, conducted in the real context of use for a prolonged period.

\section{NOTES}

Acknowledgments. We thank the teachers and children who participated in our user study. We thank our colleagues who were involved in setting up, performing, and evaluating our study. 
HCI Editorial Record. First received on April 17, 2013. Revisions received on October 8, 2013, and April 11, 2014. Accepted by Abigail Sellen. Final manuscript received on April 15, 2014. - Editor

\section{REFERENCES}

Aarts, H., \& Dijksterhuis, A. (2000). Habits as knowledge structures: Automaticity in goaldirected behavior. Journal of Personality and Social Psychology, 78, 53-63.

Alavi, H. S., Dillenbourg, P., \& Kaplan, F. (2009). Distributed awareness for class orchestration. Proceedings of the ECTEL 2009 Conference on Technology Enhanced Learning. Berlin, Germany: Springer-Verlag.

Ashbrook, D. L. (2010). Enabling mobile microinteractions (Unpublished doctoral dissertation). Georgia Institute of Technology, Atlanta.

Bakker, S., Hoven, E. van den, \& Eggen, B. (2010). Design for the periphery. Proceedings of the Eurohaptics 2010 Symposium "Haptic and Audio-Visual Stimuli: Enhancing Experiences and Interaction." CTIT Workshop Proceedings Series WP10-01.

Bakker, S., Hoven, E. van den, \& Eggen, B. (2012). Acting by hand: Informing interaction design for the periphery of people's attention. Interacting with Computers, 24, 119-130.

Bakker, S., Hoven, E. van den, \& Eggen, B. (2013). FireFlies: Physical peripheral interaction design for the everyday routine of primary school teachers. Proceedings of the TEI 2013 Conference on Tangible and Embedded Interaction. New York, NY: ACM.

Bakker, S., van den Hoven, E., Eggen, B., \& Overbeeke, K. (2012). Exploring peripheral interaction design for primary school teachers. Proceedings of the TEI 2012 Conference on Tangible, Embedded and Embodied Interaction. New York, NY: ACM.

Balaam, M., Fitzpatrick, G., Good, J., \& Luckin, R. (2010). Exploring affective technologies for the classroom with the subtle stone. Proceedings of the CHI 2010 Conference on Human Factors in Computer Systems. New York, NY: ACM.

Börner, D., Kalz, M., \& Specht, M. (2011). Thinking outside the box-A vision of ambient learning displays. International Journal of Technology Enhanced Learning, 3, 627-642.

Brown, B., Reeves, S., \& Sherwood, S. (2011). Into the wild: Challenges and opportunities for field trial methods. Proceedings of the CHI 2011 Conference on Human Factors in Computer Systems. New York, NY: ACM.

Carter, S., Mankoff, J., Klemmer, S. R., \& Matthews, T. (2008). Exiting the cleanroom: On ecological validity and ubiquitous computing. Human-Computer Interaction, 23, 47-99.

Chen, F.-H., Looi, C.-K., \& Chen, W. (2009). Integrating technology in the classroom: a visual conceptualization of teachers' knowledge, goals and beliefs. Journal of Computer Assisted Learning, 25, 470-488.

Cohen, J. (1993). "Kirk here": Using genre sounds to monitor background activity. Conference Companion of the INTERACT 1993 and CHI 1993 Conference on Human Factors in Computer Systems. New York, NY: ACM.

Dourish, P. (2001). Where the action is: The foundations of embodied interaction. Cambridge, MA: MIT Press.

Edge, D., \& Blackwell, A. F. (2009). Peripheral tangible interaction by analytic design. Proceedings of the TEI 2009 Conference on Tangible and Embedded Interaction. New York, NY: ACM. 
Eggen, B., \& Mensvoort, K. (2009). Making sense of what is going on "around": Designing environmental awareness information displays. In P. Markopoulos, B. de Ruyter, \& W. Mackay (Eds.), Awareness systems: Advances in theory, methodology and design (pp. 99-124). London, UK: Springer-Verlag.

Hausen, D., Boring, S., Lueling, C., Rodestock, S., \& Butz, A. (2012). StaTube: Facilitating state management in instant messaging systems. Proceedings of the TEI 2012 Conference on Tangible, Embedded and Embodied Interaction. New York, NY: ACM.

Hazlewood, W. R., Stolterman, E., \& Connelly, K. (2011). Issues in evaluating ambient displays in the wild: Two case studies. Proceedings of the CHI 2011 Conference on Human Factors in Computer Systems. New York, NY: ACM.

Hudson, S. E., Harrison, C., Harrison, B., L., \& LaMarca, A. (2010). Whack gestures: Inexact and inattentive interaction with mobile devices. Proceedings of the TEI 2010 Conference on Tangible and Embedded Interaction. New York, NY: ACM.

Ishii, H., \& Ullmer, B. (1997). Tangible bits: Towards seamless interfaces between people, bits and atoms. Proceedings of the CHI 1997 Conference on Human Factors in Computer Systems. New York, NY: ACM.

Ishii, H., Wisneski, C., Brave, S., Dahley, A., Gorbet, M., Ullmer, B., \& Yarin, P. (1998). ambientROOM: Integrating ambient media with architectural space. Conference Summary of the CHI 1998 Conference on Human Factors in Computer Systems. New York, NY: ACM.

Jones, S. (1992). Was there a Hawthorne effect? The American Journal of Sociology, 98, 451-468.

Kahneman, D. (1973). Attention and effort. Englewood Cliffs, NJ: Prentice-Hall.

Lamberty, K. K., Adams, S., Biatek, J., Froiland, K., \& Lapham, J. (2011). Using a large display in the periphery to support children learning through design. Proceedings of the IDC 2011 Conference on Interaction Design and Children. New York, NY: ACM.

Landis, J. R., \& Koch, G. G. (1977). The measurement of observer agreement for categorical data. Biometrics, 33, 159-174.

Lippert, S. K. (2003). Social issues in the administration of information systems survey research. In S. R. Gordon (Ed.), Computing information technology: The buman side (pp. 49-77). Hershey, PA: Idea Group Inc.

Loclair, C., Gustafson, S., \& Baudisch, P. (2010). PinchWatch: A wearable device for onehanded microinteractions. Workshop "Ensembles of On-Body Devices" at the MobileHCI 2010 Conference on Human-Computer Interaction with Mobile Devices and Services. Retrieved from http://burx.com/ensembles/

Mankoff, J., Dey, A. K., Hsieh, G., Kientz, J., Lederer, S., \& Ames, M. (2003). Heuristic evaluation of ambient displays. Proceedings of the CHI 2003 Conference on Human Factors in Computer Systems. New York, NY: ACM.

Markopoulos, P. (2009). A design framework for awareness systems. In P. Markopoulos, B. de Ruyter, \& W. Mackay (Eds.), Awareness systems: Advances in theory, methodology and design (pp. 49-72). London, UK: Springer-Verlag.

Matthews, T., Hsieh, G., \& Mankoff, J. (2009). Evaluating peripheral displays. In P. Markopoulos, B. de Ruyter, \& W. Mackay (Eds.), Awareness systems: Advances in theory, methodology and design (pp. 447-472). London, UK: Springer-Verlag.

Matthews, T., Rattenbury, T., \& Carter, S. (2007). Defining, designing, and evaluating peripheral displays: an analysis using activity theory. Human-Computer Interaction, 22, 221-261.

McCrickard, D. S., Chewar, C. M., Somervell, J. P., \& Ndiwalana, A. (2003). A model for notification systems evaluation-Assessing user goals for multitasking activity. ACM Transactions on Computer-Human Interaction, 10, 312-338. 
Norman, D. A., \& Shallice, T. (1986). Attention to action. In R. J. Davidson, G. E. Schwartz, \& D. Shapiro (Eds.), Consciousness and self-regulation (pp. 1-18). New York, NY: Springer.

Olivera, F., García-Herranz, M., Haya, P. A., \& Llinás, P. (2011). Do not disturb: Physical interfaces for parallel peripheral interactions. In P. Campos, N. Graham, J. Jorge, N. Nunes, P. Palanque, \& M. Winckler (Eds.), Human-computer interaction-INTERACT 2011 (pp. 479-486). Berlin, Germany: Springer.

Poole, A., \& Ball, L. J. (2006). Eye tracking in HCI and usability research. In C. Ghaoui (Ed.), Encyclopedia of human-computer interaction (pp. 211-219). Hershey, PA: Idea Group Inc.

Pousman, Z., \& Stasko, J. (2006). A taxonomy of ambient information systems: Four patterns of design. Proceedings of the AVI 2006 Conference on Advanced Visual Interfaces. New York, NY: ACM.

Pousman, Z., \& Stasko, J. (2007). Ambient information systems: Evaluation in two paradigms. Workshop "Ambient Information Systems" at the Pervasive 2007 Conference on Pervasive Computing. CEUR-WS.org.

Rogers, Y. (2011). Interaction design gone wild: striving for wild theory. Interactions, 18, 58-62.

Salvucci, D. D., \& Taatgen, N. A. (2008). Threaded cognition: An integrated theory of concurrent multitasking. Psychological Review, 115, 101-130.

Salvucci, D. D., \& Taatgen, N. A. (2010). The multitasking mind. New York, NY: Oxford University Press.

Schneider, W., \& Chein, J. M. (2003). Controlled \& automatic processing: Behavior, theory, and biological mechanisms. Cognitive Science, 27, 525-559.

Shallice, T., \& Burgess, P. (1993). Supervisory control of action and thought selection. In A. D. Baddeley \& L. Weiskrantz (Eds.), Attention: Selection, awareness, and control- $A$ tribute to Donald Broadbent (pp. 171-187). Oxford, UK: Oxford University Press.

Shami, N. S., Leshed, G., \& Klein, D. (2005). Context of Use Evaluation of Peripheral Displays (CUEPD). M. F. Costabile \& F. Paternò (Eds.), Human-computer interaction-INTERACT 2005 (pp. 579-587). Berlin, Germany: Springer.

Siegel, S., \& Castellan, N. J. (1988). Nomparametric statistics for the behavioral sciences (2nd ed.). Boston, MA: McGraw-Hill.

Ullmer, B., \& Ishii, H. (2000). Emerging frameworks for tangible user interfaces. IBM Systems Journal, 39, 915-931.

Weiser, M., \& Brown, J. S. (1997). The coming age of calm technology. In P. J. Denning \& R. M. Metcalfe (Eds.), Beyond calculation: The next fifty years of computing (pp. 75-85). New York, NY: Springer-Verlag.

Wickens, C. D., \& Hollands, J. G. (2000). Engineering psychology and human performance. Upper Saddle River, NJ: Prentice-Hall.

Wickens, C. D., \& McCarley, J. S. (2008). Applied attention theory. Boca Raton, FL: CRC Press.

Wippler, J. C. (2010). JeeNode: Rethinking the Arduino hardware interface. Retrieved from http://jeelabs.org/2010/12/18/rethinking-the-arduino-hardware-interface

Wolf, K., Naumann, A., Rohs, M., \& Müller, J. (2011). Taxonomy of microinteractions: Defining microgestures based on ergonomic and scenario-dependent requirements. In P. Campos, N. Graham, J. Jorge, N. Nunes, \& P. Palanque (Eds.), Human-computer interactionINTERACT 2011 (pp. 559-575). Berlin, Germany: Springer-Verlag.

Wood, W., \& Neal, D. T. (2007). A new look at habits and the habit-goal interface. Psychological Review, 114, 843-863. 